ASM Sc. J., 13, 2020

https://doi.org/10.32802/asmscj.2020.sm26(2.2)

\title{
A Multi-landfill Site Selection Model for an Effective Solid Waste Management using Greedy Heuristic: A Case Study
}

\author{
Nur Azriati Mat*, Aida Mauziah Benjamin and Syariza Abdul-Rahman \\ Institute of Strategic Industrial Decision Modelling, School of Quantitative Sciences, \\ Universiti Utara Malaysia, Kedah, Malaysia
}

\begin{abstract}
Landfills are one of the oldest, the most convenient, and the cheapest waste disposal methods, which have been widely used in the present era of urbanization worldwide. Therefore, it is undeniable that deciding the best site for landfill siting is a crucial issue in urban planning since it involves vigorous impacts on the environmental, economic, and public health aspects of the region. As such, this research points toward in guiding the local authorities in planning a multiple landfill site selection by using all available resources, which translates into being cost-effective. A well-known constructive heuristic technique called the Nearest Greedy (NG) technique had been employed to evaluate all five potential candidate locations with consideration of several related constraints. The proposed approach was tested on a real dataset of the waste collection problem in a district located at the Northern Region of Peninsular Malaysia, which consisted of 146 residential areas and involving up to 18749 unit premises. Next, the achievable solutions were compared, and the candidate landfill site with the lowest distance was selected as the best solution. The proposed solution can assist the responsible parties in managing solid waste and concurrently, serve as a guideline in identifying a suitable location to be transformed into a site for disposing of waste based on the available resources, which discards additional costs.
\end{abstract}

Keywords: landfill site selection, nearest greedy technique, resource constraint, case study, waste management

\section{INTRODUCTION}

Deciding the best location for landfill siting is a crucial issue in urban planning process since it involves vigorous effects on economic, ecology, and environmental health aspects of the region. The key objective of landfill site selection process is to identify the best location that reduces dangers to the environment and community health (Uyan, 2014). Determination of an optimum location for landfill among possible alternative locations is classified as multiple criteria decision-making problem, which involves both quantitative and qualitative criteria. Vast criteria have reflected the solution problem in the literature (Mat, et al., 2017).

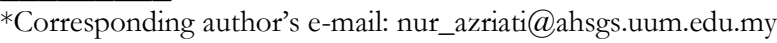

Even though foregoing studies have used a variety of criteria related to landfill site selection, preliminary design or planning activities in the utilization of the existing resources in selecting a new landfill is crucial and has been disregarded. This activity is valuable at the end of the implementation phase of a project, where the management can made plan and organize strategies for enhancement of the existing systems.

Landfill management through resource planning is effective as it can help decision-makers weigh in the probability of reducing resource usage during the process of selecting new infrastructure (i.e. landfill). This plan is ideal for long-term planning of the use of an infrastructure. In handling wastes, resources refer to workers, vehicles, fuel, or other elements that contribute to the transporting 
of wastes from a house to a disposal facility. In assigning those resources, their availability must be determined. Resource availability signifies information regarding the required resources, as well as their availability and conditions. This is because; some resources need to be arranged in advance (i.e. drivers and vehicles).

In this study, five potential locations for landfill siting were drawn based on the environmental impact assessments procedure and requirements. The selected sites were evaluated to finalize the top ranking. The literature depicts that the best solution is determined based on the secondary criteria. For instance (Wang, et al., 2009) considered the best landfill area has $500 \mathrm{~m}$ proximity to waste production center due to cost-effective transportation. Bahrani et. al., (2016) claimed that the best site is determined based on area width, soil depth, wind direction, and visibility from residential areas. As a conclusion, the evaluation criteria differ for each study. The ranking of candidate landfill sites may turn into a controversial issue due to the varying viewpoints held by multiple researchers (Ball, 2005). Hence, new ideas are being constantly tested in this study by evaluating the candidate sites based on the availability of resources that can expose the problems faced by local authorities.

The rest of the paper is organized as follows: Section 2 presents a review on the solution techniques that have been used previously in solving landfill site selection problems. Next, Section 3 describes the real dataset of waste collection problem and the technique employed to address the problem at hand, while the retrieved computational outcomes are deliberated in Section 4. Lastly, some final remarks on conclusion and several recommendations for future work are offered in Section 5.

\section{LITERATURE REVIEW}

Several decision-making techniques had been applied in the past studies to address landfill site selection issue. The landfill site selection process involves the evaluation and analysis of several criteria. The site selection process through Geographic Information System (GIS) offers valuable results that provide a cost surface map serving as a useful guideline to decision-makers in creating accurate and quick decisions (Yildirim, 2012). Arkoc (2014) exposed the necessity to select suitable landfill sites in Çorlu District, Turkey, in terms of pollution, through a combination of point count index and constraint overlaying method in GIS environment.

In line with technological advancements, the integration of GIS with multi criteria decision making (MCDM) generates a powerful and effective tool for solving landfill site selection problem due to its ability in providing efficient manipulation and presentation of spatial data, apart from supplying consistent ranking of the potential areas based on various complex criteria. For instance, Sener et. al., (2006) proposed two different types of procedures; GIS-based simple additive weighting (SAW) approach, and GIS-based Analytic Hierarchy Process (AHP) approach, to locate a suitable landfill location in Ankara, Turkey. Yal and Akgun (2013) identified the site for landfill siting in Ankara, Turkey, by integrating GIS with the Technique for Order Preference by Similarity to the Ideal Solution (TOPSIS).

Recently, Al-Ruzouq et. al., (2018) developed a fuzzyanalytical hierarchy process (F-AHP) in a geo-spatial environment for landfill site selection in the city of Sharjah, United Arab Emirates. Macro- (geo-environmental factors) and micro-level (social and economic factors) factors were considered to generate the most suitable site. Ding et. al., (2018) presented a selection of Construction and Demolition (C\&D) waste landfill sites in Shenzhen, China by integrating the triangulation of critical factor (i.e. environmental, economic, and social) using GIS and AHP methods

Depicted above are several prior studies that employed GIS, MCDM, hybrid technique, and fuzzy-based approach in addressing the problem of selecting a new landfill. Their findings appeared to be varied due to the physical conditions of the selected study areas and the criteria considered overcoming the problem. This indicates the absence of a perfect method to solve the type of problems. Hence, this paper assessed the unexplored research portion in solving the problem of selecting new landfills by considering criteria related to resource usage. This criterion is essential to construct vehicle routes for waste collection. The waste collection vehicle routing problem and the selection of a new disposal site is interconnected.

Within the context of waste collection routing, the vehicles used for the collection process are considered as resources (Belien, et al., 2012). For instance, the use of one vehicle to collect wastes throughout the research area is inadequate. Therefore, the use of more than one vehicle is a rational decision that can reduce the workload of an 
employee. A wise decision can be made by planning a vehicle routing schedule in accordance with the number of vehicles allocated for the collection process. In constructing vehicle routes, various solution methods are presented in the literature, such as mathematical programming techniques, heuristic approaches, exact methods, and simulation. Of these solution methods, the heuristic approaches are more suitable for collection routing (Belien, et al., 2012). The review of previous studies pertaining to the use of greedy algorithms in solving vehicle routing problem in various applications, including waste management, has been conducted by Mat et. al., (2017). The nearest greedy (NG) heuristic is often used to generate an initial solution before proceeding with route improvement process using metaheuristics. Hence, this NG heuristic was applied to analyze resources and to assist decision-makers in making reliable decision regarding landfill site selection. After considering the criteria related to resources, operating cost (i.e. fuel consumption) can be substantially minimized. The strategic location for landfill siting can be identified and concurrently, for devising a viable waste collection schedule.

\section{MATERIALS AND METHODS}

This section presents the real dataset of waste collection problem and the NG technique employed for this study.

\section{A. Real dataset of waste collection problem}

This study utilized the existing waste collection dataset for a district located in Kedah, Malaysia. This dataset was used to test the proposed multi-landfill site selection model by weighing in several resource constraints. In this study, a model of vehicle routing problem with time window (VRPTW) was adopted to reflect the actual situation that typically takes place in the waste management process. The problem highlighted in this study is considered as node routing problem, where the customer's location is represented by a node of network path. A total of 146 housing areas (referred as nodes) involving up to 18749 units of premises were employed in this study. The dataset features are illustrated in Table 1 as follow:

Table 1. Dataset features

\begin{tabular}{|l|l|}
\hline Number of housing areas & 146 units \\
\hline Number of depots & One \\
\hline
\end{tabular}

\begin{tabular}{|l|l|}
\hline $\begin{array}{l}\text { Potential landfill } \\
\text { candidates }\end{array}$ & Five \\
\hline Vehicle capacity & $7000 \mathrm{~kg}$ \\
\hline Vehicle travel speed & $40 \mathrm{~km} / \mathrm{h}$ \\
\hline Driver's lunch break & One hour \\
\hline Time windows & $\begin{array}{l}\text { Customer and landfill (8 } \\
\text { am }-8 \mathrm{pm}) \\
\text { Depot (8 am }-9 \text { pm) }\end{array}$ \\
\hline Service time & 20 secs each premise \\
\hline Customer demands & $4 \mathrm{~kg}$ each premise \\
\hline
\end{tabular}

In this research, the candidate landfill locations were determined based on assumption. Google Earth was used manually to identify the locations of free land areas (unused or agricultural land), which are located farther from residential areas. In fact, some guidelines were adhered to determine the permissible distance between the located landfill sites and the residential areas, as stipulated in the law. A minimum buffer zone of $3000 \mathrm{~m}$ was considered in this research. However, as mentioned before, this is merely an assumption, whereby field work determination is recommended to obtain more reliable locations.

\section{B. Greedy technique for a multi-landfill site selection model}

This study is an extension of the work presented by Mat et. al., (2018), where the particular study proposed a single landfill site selection model by weighing in resource requirements. Hence, this study enhanced the issue by introducing a multi-landfill site selection model. For that purpose, the NG technique was adopted from the work carried out by Mat et. al., $(2017,2018)$ generate initial solutions for a real dataset waste collection problem. Fundamentally, in solving the problem linked with waste collection, the NG technique selected the nearest customer from the current node to be served based on several constraints associated to depot, customer, landfill site, vehicle, and operational, as presented in the research by Mat et. al., (2018). In this research, the NG technique was adopted to construct vehicle routes in order to address waste collection issue. As such, a new set of initial solutions was constructed based on the number of candidate landfill sites. For example, five landfill sites were identified. In the 
scope of this study, the combination of landfill for a multilandfill model was constructed based on the possibilities of two landfills, three landfills, four landfills, and all landfills selected, thus representing twenty-three initial solutions for comparison at the end of the analysis. The total number of stops for each landfill site was calculated as ( $\mathrm{n}+$ one depot $+\mathrm{m}$ landfill site), where $\mathrm{n}$ refers to the total customers served. Each node was defined based on ID, which is o for depot $\{1, \ldots, \mathrm{n}\}, \mathrm{n}$ for customers, and $\mathrm{m}$ for the number of landfill sites. A new vehicle route was constructed from node $\mathrm{O}$. After that, the nearest customer from node o was identified by using the NG technique. During this process, the distance between $\mathrm{o}$ and $\mathrm{n}$ customers was compared. The selected node with the lowest distance was added to the present vehicle route, while the remaining customers yet to be served were updated. The vehicle capacity was determined soon after each customer was served.

If the vehicle was fully loaded with waste, they would need to dispose the collected waste into landfill site $\{n+1\}$. The process continued until all customers were served.
Before returning to node 0 , the vehicle load would have to be emptied at the landfill site. As such, the algorithm calculated the total travel distance by the vehicle and the total time required by the drivers to complete the waste collection process. Finally, the algorithm was terminated. The candidate landfill site with the lowest distance emerged as the best optimal solution.

\section{RESULTS AND DISCUSSION}

In this paper, the proposed algorithms that solved waste collection VRPTW (WC-VRPTW) were run on a Pentium $®$ Dual-Core CPU T4300 @ 2.10GHz with 3.00 GB memory using $\mathrm{C}++$ language. Table 2 presents the comparison of the computational outcomes between the current operating landfill site, single landfill site, and multi-landfill site (two until five landfills). The solutions were compared in terms of total distance, total travel time, and the number of drivers required to complete the waste collection process for landfill site selection planning.

Table 2. Computational results for current, single, and multi-landfill site selection

\begin{tabular}{|c|c|c|c|c|}
\hline $\begin{array}{l}\text { Landfill } \\
\text { location }\end{array}$ & $\begin{array}{c}\text { Total distance } \\
\text { (km) }\end{array}$ & $\begin{array}{c}\text { Total travel time } \\
\text { (secs) }\end{array}$ & $\begin{array}{l}\text { Number of } \\
\text { drivers }\end{array}$ & $\begin{array}{c}\text { Computational time } \\
\text { (secs) }\end{array}$ \\
\hline \multicolumn{5}{|c|}{ Current landfill (Single) } \\
\hline & 702.963 & 52416.1 & 11 & 0.188 \\
\hline \multicolumn{5}{|c|}{ Single landfill* } \\
\hline 1 & 1004.16 & 74874.8 & 11 & 0.195 \\
\hline 2 & 953.734 & 71114.7 & 11 & 0.187 \\
\hline 3 & 973.978 & 72624.2 & 11 & 0.177 \\
\hline 4 & $655 \cdot 562$ & 48881.7 & 11 & 0.157 \\
\hline 5 & 1011.05 & 75388.8 & 11 & 0.291 \\
\hline \multicolumn{5}{|c|}{ Two landfills } \\
\hline 1,2 & 949.783 & 70820.2 & 11 & 0.254 \\
\hline 1,3 & 983.452 & 73330.7 & 11 & 0.279 \\
\hline 1,4 & 751.771 & 56055.5 & 11 & 0.27 \\
\hline 1,5 & 978.473 & 72959.4 & 11 & 0.155 \\
\hline 2,3 & 961.636 & 71704 & 11 & 0.191 \\
\hline 2,4 & 658.776 & 49121.4 & 11 & 0.166 \\
\hline 2,5 & 969.158 & 72264.8 & 11 & 0.158 \\
\hline 3,4 & 656.941 & 48984.5 & 11 & 0.154 \\
\hline 3,5 & 1005.72 & 74991.2 & 11 & 0.159 \\
\hline 4,5 & 1004.7 & 74915.2 & 11 & 0.167 \\
\hline \multicolumn{5}{|c|}{ Three landfills } \\
\hline $1,2,3$ & 948.096 & 70694.4 & 11 & 0.272 \\
\hline
\end{tabular}




\begin{tabular}{|c|c|c|c|c|}
\hline $1,2,4$ & 747.704 & $5575^{2.2}$ & 11 & 0.167 \\
\hline $1,2,5$ & 946.486 & 70574.3 & 11 & 0.158 \\
\hline $1,3,4$ & 843.842 & 62920.7 & 11 & 0.22 \\
\hline $1,3,5$ & 978.473 & 72959.4 & 11 & 0.286 \\
\hline $1,4,5$ & 723.93 & 53979.6 & 11 & 0.159 \\
\hline $2,3,4$ & 732.443 & $54614 \cdot 3$ & 11 & 0.295 \\
\hline $2,3,5$ & 969.539 & $72293 \cdot 3$ & 11 & 0.158 \\
\hline $2,4,5$ & $687 \cdot 373$ & $51253 \cdot 7$ & 11 & 0.161 \\
\hline $3,4,5$ & 708.386 & 52820.5 & 11 & 0.158 \\
\hline \multicolumn{5}{|c|}{ Four landfills } \\
\hline $1,2,3,4$ & 744.195 & 55490.6 & 11 & 0.159 \\
\hline $1,2,3,5$ & 940.913 & 70158.8 & 11 & 0.159 \\
\hline $1,2,4,5$ & 699.125 & 52130 & 11 & 0.16 \\
\hline $1,3,4,5$ & 720.138 & 53696.8 & 11 & 0.166 \\
\hline $2,3,4,5$ & 707.458 & 52751.3 & 11 & 0.159 \\
\hline \multicolumn{5}{|c|}{ Five landfills } \\
\hline $1,2,3,4,5$ & 719.21 & 53627.6 & 11 & 0.161 \\
\hline
\end{tabular}

*Mat et al. (2018)

The computational results presented in Table 2 display the resources required to provide service to 18,749 units of premises based on five different landfill sites. The solutions from the analysis are divided into seven sub-solutions (i.e. current landfill, two landfills, three landfills, four landfills and five landfills). Two landfills and above were denoted as multi-landfill.

In view of the analysis for the proposed solution, for the single landfill category, candidate landfill 4 appeared as the best alternative, in comparison to other candidate sites, whereby the total distance travelled by all drivers was $655.562 \mathrm{~km}$ (a decrease by $6.74 \%$, as compared to the current landfill site). The time taken to complete all the vehicle routes was approximately 13 hours and 58 minutes.

Meanwhile, for the multi-landfill category, two landfills, which are a combination of candidate landfills 3 and 4, appeared as the best alternative site, when compared to other combination landfills. The total distance travelled by all drivers was $656.941 \mathrm{~km}$ (a decrease by $6.77 \%$, as compared to the current operating landfill site). Nevertheless, the local authorities would need to hire eleven drivers for all landfills to complete the waste collection process. Overall, based on the result of the analysis between single model and multi model, the single model appeared to be the best choice. Nevertheless, if the authorities intend to build more than one landfill, (i.e. multi-landfill), the multi-model proposed in this paper may be applied as a reference or guidelines.
However, this is merely a case study research. Each study area is bound to generate outputs based on geographical conditions of an area.

In addition, multi-models also have advantages in terms of landfill lifespan. For instance, if the lifespan for a landfill is 5 years, with the use of more than one landfill, the waste collected from the customer can be divided according to the number of landfills (based on the nearest distance from landfill sites to customers). This makes the lifespan for one site last longer.

\section{CONCLUSION AND FUTURE WORK}

This study developed a model to select the best landfill site after considering resource requirements. A constructive heuristic technique was used to identify and to choose the best site. Additionally, the constraints related to WCVRPTW were also weighed in. For reader's knowledge, various resources can be included based on the problem areas. This study displays the use of NG technique as a tool in solving this problem. The NG technique was one of the algorithms used to determine a solution for vehicle routing problem. The study outcomes exhibit the comparison of solutions for two different models. This solution from single model was adopted from the author's prior research discussed at international conferences. This present study enhances the previous model by proposing a multi-landfill 
site selection model. The results showed that a single model is the best model for this case study. Anyhow, a different study area will produce various outputs based on the geographical conditions of an area.

Therefore, one can conclude that resource requirements, such as drivers and travel distance of the vehicles, do exert a huge effect on landfill site selection process. This study sums up that the decision made by the authorities to choose either a landfill or more depends on their construction costs. The fact is, there are pros and cons to choosing a multi-landfill and amongst them is the high cost of construction. However, although the cost for the construction of two sites was high, the lifespan of each site is longer than the reliance only on a single landfill. In the near future, the authors would like to investigate other resource requirements that may affect the landfill site selection process in the attempt of gaining more practical solutions.

\section{ACKNOWLEDGEMENT}

The authors would like to express their gratitude to the Institute of Strategic Industrial Decision Modelling, the Malaysian Ministry of Higher Education for supporting and providing the research funding under the Fundamental Research Grant Scheme (Code: 13225), as well as the Research and Innovation Management Centre, Universiti Utara Malaysia for the administration of this research.

\section{REFERENCES}

Uyan, M. 2014, MSW landfill site selection by combining AHP with GIS for Konya, Turkey. Environmental Earth Sciences, 71(4), 1629-1639.

Mat, N. A., Benjamin, A. M., \& Abdul-Rahman, S. 2017, A review on criteria and decision-making techniques in solving landfill site selection problems. Journal of Advanced Review on Scientific Research, 37(1), 14-32.

Wang, G., Qin, L., Li, G., \& Chen, L. 2009, Landfill site selection using spatial information technologies and AHP: A case study in Beijing, China. Journal of Environmnetal Management, 90(8), 2414-2421.

Bahrani, S., Ebadi, T., Ehsani, H., Yousefi, H., \& Maknoon, R. 2016, Modeling landfill site selection by multi-criteria decision making and fuzzy functions in GIS, case study: Shabestar, Iran. Environmental Earth Sciences, 75(4), 337.

Ball, J. M. 2005, Landfill site selection. In Tenth International Waste Management and Landfill Symposium (pp. 3-7). S. Margherita di Pula, Cagliari, Italy. 
Yildirim, V. 2012, Application of raster-based GIS techniques in the siting of landfills in Trabzon Province, Turkey: A case study. Waste Management \& Research, 30(9), 949-960.

Arkoc, O. 2014, Municipal solid waste landfill site selection using geographical information systems: A case study from Çorlu, Turkey. Arabian Journal of Geosciences, 7(11), 4975-4985.

Sener, B., Suzen, M. L., \& Doyuran, V. 2006, Landfill site selection by using geographic information systems. Environmental Geology, 49(3), 376-388.

Yal, G. P., \& Akgun, H. 2013, Landfill site selection and landfill liner design for Ankara, Turkey. Environmental Earth Sciences, 70(6), 2729-2752.

Al-Ruzouq, R., Shanableh, A., Omar, M., \& AlKhayyat, G. 2018, Macro and micro geo-spatial environment consideration for landfill site selection in Sharjah, United Arab Emirates. Environmental Monitoring and Assessment, 190(3), 147.

Ding, Z., Zhu, M., Wang, Y., \& Zhu, J. 2018,. An AHPGIS based model of C\&D waste landfill site selection: A triangulation of critical factors. In Proceedings of the 21st International Symposium on Advancement of Construction Management and Real Estate (pp. 163-174). Singapore: Springer.

Belien, J., Boeck, L. D., \& Ackere, J. V. 2012, Municipal solid waste collection and management problems: A literature review. Transportation Science, 48(1), 78-102.

Mat, N. A., Benjamin, A. M., Abdul-Rahman, S., \& Wibowo, A. 2017, Nearest greedy for solving the waste collection vehicle routing problem : A case study. In AIP Conference Proceedings (Vol 1905, No. 1), pp. 40018-1-40016-6.

Mat, N. A., Benjamin, A. M., \& Abdul-Rahman, S. 2018, Resource Planning For a Single Landfill Site Selection Model Based on Greedy Strategy: A Case Study. The Journal of Social Sciences Research, Special Issue. 6, 607-614.
Mat, N. A., Benjamin, A. M., \& Abdul-Rahman, S. 2018, Efficiency of Heuristic Algorithms in Solving Waste Collection Vehicle Routing Problem: A Case Study. The Journal of Social Sciences Research, Special Issue. 6, 695-700. 